\title{
Quantitative, Label-Free Detection of the Aggregation of $\alpha$-Synuclein Using Microcantilever Arrays Operated in a Liquid Environment
}

\author{
Jason Jensen, ${ }^{1}$ Margherita Farina, ${ }^{2}$ Giampaolo Zuccheri, ${ }^{2}$ Wilfried Grange, ${ }^{3}$ \\ and Martin Hegner ${ }^{1}$ \\ ${ }^{1}$ Centre for Research on Adaptive Nanostructures and Nanodevices (CRANN) and School of Physics, Trinity College Dublin, \\ Dublin 2, Ireland \\ ${ }^{2}$ Department of Biochemistry, University of Bologna, 40126 Bologna, Italy \\ ${ }^{3}$ Institut Jacques Monod, CNRS, Université Paris Diderot, 75205 Paris Cedex 13, France
}

Correspondence should be addressed to Jason Jensen, jensenja@tcd.ie and Martin Hegner, hegnerm@tcd.ie

Received 15 June 2011; Accepted 15 August 2011

Academic Editor: Maria Tenje

Copyright (c) 2012 Jason Jensen et al. This is an open access article distributed under the Creative Commons Attribution License, which permits unrestricted use, distribution, and reproduction in any medium, provided the original work is properly cited.

\begin{abstract}
Early detection of protein aggregation is of great importance in the field of neurodegenerative diseases. The successful detection of the aggregation of the protein $\alpha$-synuclein in a quantitative, label-free manner by functionalising a microcantilever with $\alpha$ synuclein monomers and operating it in dynamic mode in the presence of $\alpha$-synuclein monomers in solution is reported. A total mass of $6 \mathrm{ng}$ of $\alpha$-synuclein was detected over 9 hours on the surface of the cantilever. The result is compared to conventional fluorescence measurements of $\alpha$-synuclein aggregation under similar conditions. It is found that the label-free cantilever detection method requires a concentration of protein 50 times smaller than that of the current method and indicated potential for significantly faster response times.
\end{abstract}

\section{Introduction}

Parkinson's disease is a progressive, neurodegenerative disorder which was first described by James Parkinson in 1817 [1]. It is the second most common neurodegenerative disorder and affects $1-2 \%$ of the population over the age of 65 years [2]. Parkinson's disease has been associated with mutations of the gene encoding for, and the aggregation of, the protein $\alpha$-synuclein which is highly expressed in the dopamine containing neurons in the substantia nigra [2-6].

The neuropathological feature of Parkinson's disease is the presence of cytoplasmic inclusions called Lewy bodies which are fibrillar aggregates of $\alpha$-synuclein [7-9]. The amyloid fibrils are $200-600 \mathrm{~nm}$ long and $5-10 \mathrm{~nm}$ in diameter $[2,3,6,10] . \alpha$-Synuclein belongs to the group of natively unfolded proteins and contains 140 amino acid residues $[11,12]$. Animal models indicate that the accumulation of $\alpha$ synuclein may play a role in the loss of dopaminergic neurons during Parkinson's disease [13-15].
Thioflavin $\mathrm{T}$ is a fluorescent label for $\alpha$-synuclein which undergoes a shift in emission frequency upon aggregation of the protein [16-18]. By monitoring, the intensity of the shifted emission frequency rates of aggregation of the protein can be determined [16]. However, this technique requires knowledge of the label-fibril binding stoichiometries which can be variable depending on solution conditions or type of protein being investigated. $\alpha$-Synuclein aggregation rates determined using Thioflavin $\mathrm{T}$ show a strong dependence on solution conditions such as $\mathrm{pH}$ or salt concentration, with incubation times (at $37^{\circ} \mathrm{C}$ ) for achieving half the final intensity being $\sim 80$ hrs at $\mathrm{pH} 7$ and as short as 70 minutes at $\mathrm{pH} 4$ [16]. Typically large concentrations of the protein are also required to provide sufficient intensity for measurement. Also the presence of another molecule which interacts with the fibril can affect binding kinetics; therefore, label-free detection techniques which do not affect the kinetics are preferable [19]. 
Nanomechanical cantilever sensors have been widely applied in the field of biology due to their versatility and easy functionalisation with a broad range of chemical and biological molecules. These sensors can be operated in liquid [20] which allows detection of the target molecules and interactions in a physiological environment. Cantilever sensors have found applications in the fields of genomics [21-25], microbiology [26-30], detection of proteins [31], as immunosensors [32] and for the investigation of membrane protein-ligand interactions $[33,34]$.

Label-free detection of growth of insulin amyloid fibrils by measuring the deflection of a microcantilever has been reported [35]. However, this method only reported the tracking of deflection of the cantilever with time and the surface stress induced on the cantilever by the growth of the fibrils and as such is suitable for determining whether or not growth of the fibril is occurring and is not suitable for determining the kinetics of the interaction in a quantitative manner.

When operated in dynamic mode the cantilever is vibrated at one of its flexural resonance frequencies and acts as a fine microbalance which allows quantitative measurements to be conducted. The dynamics of microcantilevers operating in fluids are well documented in the literature both theoretically [36-43] and experimentally [38, 44, 45] due to the importance of understanding their behaviour for use with atomic force microscopes. Operation of the microcantilever in liquid for the entire experiment avoids any phase changes (e.g., liquid to air) which occur during other experiment designs, such as "dip and dry" measurements [46], which could cause damage to the protein being investigated. "Dip and dry" measurements can also lead to unwanted precipitation of the buffer salts onto the surface of the sensor. This precipitation can lead to additional mass on the surface which can convolute the signal measured by the sensor and lead to uncertainty in the interpretation of results. In order to increase mass sensitivity, high modes of vibration of the cantilever can be used to regain some of the sensitivity which is lost due to damping when operating the cantilever in liquid instead of air or vacuum [47].

Here measurements of aggregation of $\alpha$-synuclein using the label Thioflavin $\mathrm{T}$ and fluorescence measurements are compared with label-free detection using microcantilevers.

\section{Materials and Methods}

\subsection{Cantilever Measurements}

2.1.1. Preparation of Cantilever Array. Microcantilevers can respond to virtually any stimulus as is shown by the wide range of sensing applications that they have been applied to. Therefore, careful preparation of the cantilever array is essential to create a sensor that is both sensitive to the mass change due to the aggregation on the surface and also specific to the desired interaction. The use of a reference in sensing applications involving cantilevers is essential if the correct deductions are to be taken from the recorded response of the cantilevers. The cantilevers used in these experiments were $\mathrm{Si}$ cantilever arrays (Orientation: 110) with eight cantilevers per array (IBM Research Laboratory, Rüschlikon, Switzerland). The cantilevers had a pitch of $250 \mu \mathrm{m}$ and were $500 \mu \mathrm{m}$ long, $100 \mu \mathrm{m}$ wide, and $1 \mu \mathrm{m}$ thick (with a $10 \mathrm{~nm}$ tolerance of the thickness within an array). The use of an array of cantilevers allows the inclusion of multiple tests and in situ references in one experiment. This greatly increases throughput and ensures that unwanted responses of the test cantilevers can be taken into account.

2.1.2. Cleaning. Unless otherwise stated all chemicals are from Sigma-Aldrich (Arklow, Ireland). The cantilever array was cleaned using the following protocol. A precleaning step in 2\% RBS detergent solution (Fluka) for 2 minutes was followed by a rinse in $1 \mathrm{M} \mathrm{NaCl}$ and a rinse in $18 \mathrm{M} \Omega$ nanopure water (30 seconds each). The array was then placed in piranha solution $\left(1: 1\right.$ ratio of $\mathrm{H}_{2} \mathrm{SO}_{4}: \mathrm{H}_{2} \mathrm{O}_{2}$ ) for 30 seconds followed by rinses in $1 \mathrm{M} \mathrm{NaCl}, \mathrm{EtOH}$ and $18 \mathrm{M} \Omega$ nanopure water mix ( $1: 1$ ratio), and $18 \mathrm{M} \Omega$ nanopure water for 30 seconds each. The array was then placed in piranha baths for 20 and 10 minute periods with the same rinse procedure as before following each bath. The cantilever array was then placed in an isopropanol bath for 2 minutes before being stored in vacuum until needed.

2.1.3. Ti/Au Coating and Functionalisation. The cantilever array was coated in a monolayer of PEG silane by immersing the array in a solution of $4900 \mu \mathrm{L} \mathrm{EtOH}$, $50 \mu \mathrm{L}$ Hunig's base(N-ethyldiisopropylamine), and $50 \mu \mathrm{L}$ [hydroxy(polyethyleneoxy)propyl] triethoxysilane (8-12 EO) $50 \%$ in $\mathrm{EtOH}$ (ABCR GmbH \& Co., 76187 Karlsruhe, Germany) for 2 hours on a linear shaker at 120 RPM.

The cantilever array was then coated on the top side with a $2 \mathrm{~nm}$ Ti adhesion layer followed by a $20 \mathrm{~nm} \mathrm{Au}$ layer (Birmingham Metals Ltd., Birmingham, B9 4BN, UK). The metal coating was carried out by e-beam evaporation for the $\mathrm{Ti}$ and thermal evaporation for the Au (Edwards Auto 500, BOC Edwards, West Sussex, RH10 9LW, UK). The settings used were Ti: pressure $4.3 \times 10^{-7}$ Torr, $46 \mathrm{~mA}$ current, with a deposition rate of $0.4 \AA / \mathrm{s}$; Au: pressure $5.4 \times$ $10^{-7}$ Torr, $12 \mathrm{~mA}$ current with a deposition rate of $1.5 \AA / \mathrm{s}$. The cantilever array was stored in vacuum until needed for functionalisation.

The cantilever array was functionalised using a custom fabricated capillary functionalisation setup [48]. The capillaries had an outer diameter of $250 \mu \mathrm{m}$ and an inner diameter of $180 \mu \mathrm{m}$ (King Precision Glass Inc, Calif, USA). The cantilevers were inserted into the end of the capillaries, and the capillaries were then back filled with the solution for functionalisation. The test cantilevers were first coated with a monolayer of DSU (dithobis(succinimidyl undecanoate), NBS Biologicals) [49] by immersion in a solution of $0.5 \mathrm{mM}$ DSU in dioxane 1,4 for 30 minutes. The DSU binds to the gold via a thiol group at one end. The reference cantilevers were passivated against protein binding using a hydroxylterminated monolayer. The layer was formed by immersing the cantilevers in a solution of $0.5 \mathrm{mM} 11$-mercapto-1undecanol in $\mathrm{EtOH}$ for 30 minutes. The array was then rinsed in dioxane 1,4 for 5 minutes followed by EtOH for 3 minutes. The test cantilevers were then further functionalised 
with wild type $\alpha$-synuclein protein (r-Peptide, Bogart, Ga, USA), which binds to the DSU, by immersion in $5 \mu \mathrm{g} / \mathrm{mL}$ $\alpha$-synuclein in sodium phosphate buffer $(20 \mathrm{mM}, \mathrm{pH} 7)$ for 2 hours. This was followed by a rinse in the same buffer for 5 minutes. Any remaining binding sites on the cantilever array were blocked using BSA (bovine serum albumin) at a concentration of $0.1 \mathrm{mg} / \mathrm{mL}$ in phosphate buffer $(20 \mathrm{mM}, \mathrm{pH}$ 7.0). The BSA solution was sonicated and filtered through a $0.2 \mu \mathrm{m}$ filter to remove any aggregates prior to immersion of the cantilever array in the solution. A final schematic of the functionalised test and reference cantilevers is shown in Figure 1.

2.1.4. Dynamic Mode Device. The cantilevers are clamped on top of a piezo electric actuator (EBL Products Inc., East Hartford, Conn, USA) inside the fluidic chamber. The cantilevers were excited at various flexural vibrating modes by a linear frequency sweep of a sinusoidal signal which is provided by a frequency generator (NI PCI 5406, National Instruments, Tex, USA) which is controlled by a LabVIEW interface.

As shown in Figure 2, optical beam deflection was used to detect the resonance frequency of the cantilever vibrations. A laser beam $(633 \mathrm{~nm}$, Free space power $>2.4 \mathrm{~mW}$, SWL 7504-P, Newport, Calif, USA) attenuated by a neutral density filter (OD 1.3 NE513B; Thorlabs Cambridgeshire, CB7 4EX, UK) was deflected from the tip of the cantilever onto a linear position sensitive detector (PSD, Sitek, Partille, Sweden). The output from the PSD is amplified (SR560 Low-Noise Preamplifier, Stanford Research Systems, Calif, USA) and digitised (NI PCI 5112, National Instruments, Tex, USA) before being analysed with the output from the frequency generator in a LabVIEW program resulting in a frequency spectrum. An automated translation stage (M110.1DG, Physik Instrumente, Bedford, MK43 0AN, UK) controlled by the LabVIEW program was used to move the laser and allow sequential readout from each of the cantilevers in the array.

The entire device is housed inside a box which is kept at a constant temperature of $23 \pm 0.1^{\circ} \mathrm{C}$ to avoid any drifts in the measurement due to temperature changes. The temperature is kept constant by a fuzzy logic controller which is implemented using LabVIEW.

Fluid was pumped through the fluidic chamber using a syringe pump (Kent Scientific Corporation, Conn, USA). A $1.8 \mathrm{~mL}$ injection loop was used to inject target molecules without breaking the flow through the chamber.

2.1.5. Measurement. The array was loaded into the dynamic mode fluidic chamber and clamped on top of the piezo actuator. Sodium phosphate buffer $(20 \mathrm{mM}, \mathrm{pH}$ 6.0) was passed through the chamber at a rate of $3.3 \mu \mathrm{L} / \mathrm{min}$ for four hours to allow the $\alpha$-synuclein on the surface of the cantilevers to equilibrate to the lower $\mathrm{pH}$ and also to establish a baseline from which the shift of resonance frequency could be measured.

$\alpha$-Synuclein lyophilised in Tris was resuspended in $18 \mathrm{M} \Omega$ nanopure water to a final concentration of $1 \mathrm{mg} / \mathrm{mL}$ $\alpha$-synuclein in $10 \mathrm{mM}$ Tris, $\mathrm{pH}$ 7.4. The $\alpha$-synuclein was

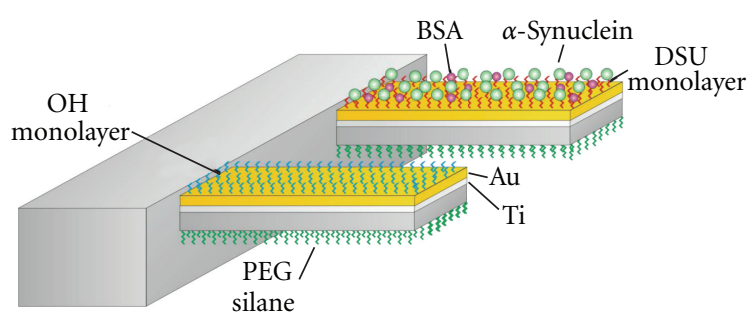

FIGURE 1: Schematic showing the functionalisation of the cantilever array. The backside of the cantilever is coated with a PEG silane monolayer to prevent nonspecific adsorption of $\alpha$-synuclein during the experiment. The array is coated with a Ti/Au layer to facilitate functionalisation using thiol chemistry. The reference cantilever is coated with a self-assembled $\mathrm{OH}$ monolayer. The test cantilever is coated with $\alpha$-synuclein bound to a DSU monolayer. All remaining binding sites are blocked with BSA.

rebuffered in $20 \mathrm{mM}$ sodium phosphate buffer, $\mathrm{pH}$ 6, using a protein desalting spin column (Pierce Protein Research Products, Fisher Scientific Ireland, Dublin, Ireland). The solution was then diluted down to a final concentration of $10 \mu \mathrm{g} / \mathrm{mL}$ in the same buffer.

The $\alpha$-synuclein monomers were passed through the fluidic chamber at a rate of $3.3 \mu \mathrm{L} / \mathrm{min}$. In total, $1.8 \mathrm{~mL}$ of the monomer solution was passed over the array. Following the injection of the monomer solution, phosphate buffer was passed through the chamber to check for any unbinding of protein from the surface of the cantilever.

2.1.6. Data Handling. The 14th flexural resonance mode of the cantilever $(\sim 640 \mathrm{kHz})$ was tracked during the experiment. The frequency range of each scan was $200 \mathrm{kHz}$, with 2000 steps in the range giving a frequency resolution of $100 \mathrm{~Hz}$. Each frequency in the range was excited for $1 \mathrm{~ms}$, and the response from the PSD was sampled at a rate of $10^{6}$ samples per second. The RMS value of the differential signal from the PSD was then calculated for each of the frequencies in the spectrum. The resonance mode was measured every 30 seconds for each cantilever in the array. The bound mass on the surface of the cantilevers was then extracted from the frequency spectra by postprocessing of the data using NOSEtools software [50-52].

2.2. Fluorescence Measurements. The aggregation of the protein $\alpha$-synuclein in solution was also measured using fluorescence measurements as a further control to be compared with the cantilever array measurement. The fluorescent marker Thioflavin $\mathrm{T}$ was used to indicate aggregation of the $\alpha$ synuclein in solution.

2.2.1. Preparation of $\alpha$-Synuclein. The $\alpha$-synuclein lyophilised in Tris was resuspended in $18 \mathrm{M} \Omega$ nanopure water to a final concentration of $1 \mathrm{mg} / \mathrm{mL} \alpha$-synuclein in $10 \mathrm{mM}$ Tris, $\mathrm{pH}$ 7.4. The protein was resuspended in $10 \mathrm{mM}$ sodium phosphate buffer, $\mathrm{pH}$ 7.4, using a dialysis membrane (Slide-A-Lyzer Dialysis Cassette 3,500 MWCO, Pierce Protein Research Products, Fisher Scientific Ireland, Dublin, 


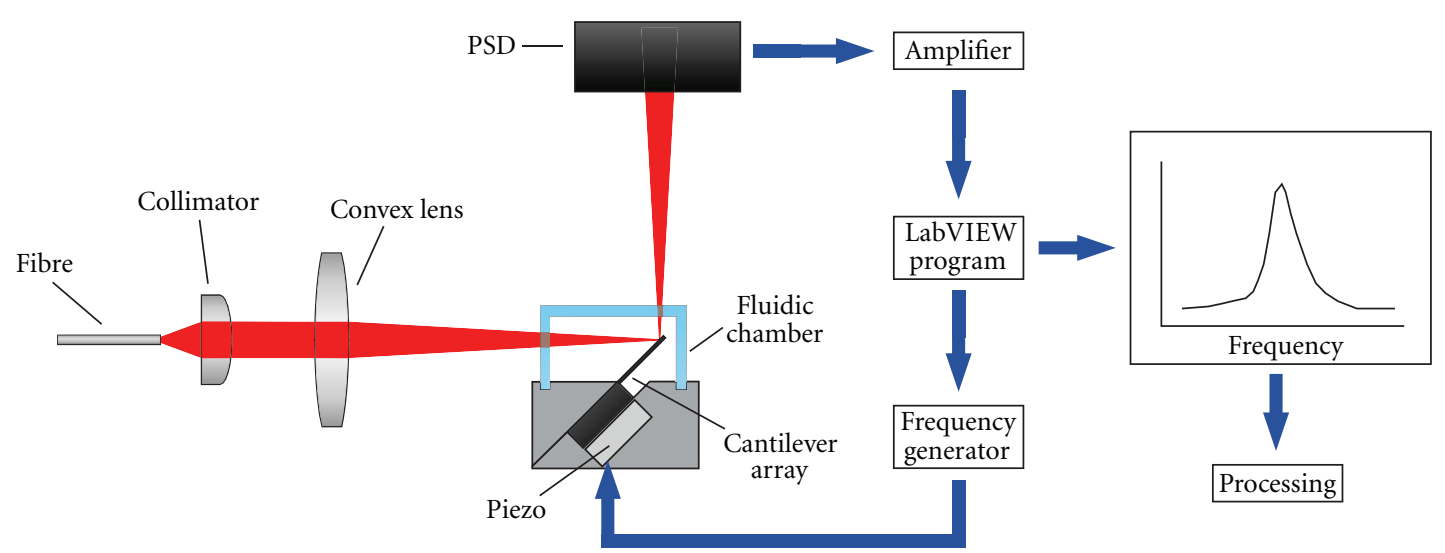

FIGURE 2: Schematic of the experimental device and measurement procedure. A LabVIEW program controls a frequency generator which sends a sinusoidal frequency signal to the piezo actuator. The cantilever is swept through a range of frequencies, and the response of the cantilever is detected using optical beam deflection. The signal from the PSD is then amplified before being processed by the LabVIEW program to create a frequency spectrum. The peaks of the frequency spectrum correspond to the flexural resonance modes of the cantilever. The frequency spectra generated during the experiment are then processed to give a frequency versus time plot, and hence the change in bound mass versus time can be determined.

Ireland). The $1 \mathrm{~mL}$ of protein in Tris solution was injected into the membrane and placed in $800 \mathrm{~mL}$ of the sodium phosphate buffer for 30 hours and stored at $4^{\circ} \mathrm{C}$. The sodium phosphate buffer was replaced three times during the procedure.

2.2.2. Fluorescence Measurements. A 96-well microtiter plate (Sterilin Ltd., Newport, NP11 3EF, UK) was prepared with wells containing $30 \mu \mathrm{L}$ of $10 \mathrm{mM}$ sodium phosphate buffer ( $\mathrm{pH} 7.4$ ), $10 \mu \mathrm{L}$ of $500 \mathrm{mM} \mathrm{NaCl}$ in $10 \mathrm{mM}$ buffer, $50 \mu \mathrm{L}$ of $\alpha$-synuclein $1 \mathrm{mg} / \mathrm{mL}$ in $10 \mathrm{mM}$ buffer and $10 \mu \mathrm{L}$ of $100 \mu \mathrm{M}$ Thioflavin-T in $10 \mathrm{mM}$ buffer for a final volume of $100 \mu \mathrm{L}$ in each well. Reference wells for Thioflavin $\mathrm{T}$ and blank measurements were also prepared. The reference well for Thioflavin $\mathrm{T}$ contained $80 \mu \mathrm{L}$ of $10 \mathrm{mM}$ buffer, $10 \mu \mathrm{L}$ of $500 \mathrm{mM} \mathrm{NaCl}$ in $10 \mathrm{mM}$ buffer and $10 \mu \mathrm{L}$ of $100 \mu \mathrm{M}$ Thioflavin-T in $10 \mathrm{mM}$ buffer. The blank reference wells contained $90 \mu \mathrm{L}$ of $10 \mathrm{mM}$ buffer, and $10 \mu \mathrm{L}$ of $500 \mathrm{mM}$ $\mathrm{NaCl}$ in $10 \mathrm{mM}$ buffer. Two wells of each of the above were prepared at three time intervals $8 \mathrm{hrs}$ apart to facilitate measurements of the aggregation at equally spaced time intervals.

The plates were incubated at $37^{\circ} \mathrm{C}$ while shaking continuously at $150 \mathrm{RPM}$, with a diameter of $20 \mathrm{~mm}$. The plates were removed from the incubator for intensity measurements every 2.5 hours. The plates were covered at all times to avoid photo bleaching of the Thioflavin T. The fluorescence measurements were carried out in a FLUOstar Optima microplate multidetection reader (BMG Labtech, Aylesbury, HP20 2QJ, UK) with excitation at $450 \mathrm{~nm}$ and emission intensity recorded at $520 \mathrm{~nm}$.

\section{Results and Discussion}

3.1. Cantilever Measurements. The frequency spectra resulting from the cantilever measurements were postprocessed using NOSEtools software to determine the shift of the flexural resonance peak and hence the change in mass on the surface of the cantilever (Figure 3). The reference cantilever demonstrated a small decrease in frequency during the experiment (data not shown). The response from the reference cantilever was subtracted from that of the test cantilever to account for any nonspecific adsorption of protein to the either side (PEG back side or $\mathrm{OH}$ terminated top side) of the cantilever and to account for any drifts in the response. The only sites available for the $\alpha$-synuclein monomers in solution to bind to the surface of the cantilever was by aggregating and starting its polymerisation with the protein already attached to the DSU monolayer on the surface. Approximately, $6 \mathrm{ng}$ of protein was aggregated on the surface of the cantilever over a 9-hour period. Following the injection of monomers buffer was passed through the chamber and a small amount of $\alpha$-synuclein was removed from the surface $(\sim 1 \mathrm{ng})$.

Images of the top side of the test and reference cantilevers following the experiment indicate that more protein was bound to the surface of the test cantilever than the reference (data not shown) and support the frequency measurements that indicate that there was a small amount of nonspecific binding of the $\alpha$-synuclein to the reference cantilever. This highlights the importance of the in situ reference when conducting experiments of this kind. The subtraction of the response of the reference cantilever from that of the test cantilever allows any nonspecific binding of the protein to be subtracted from the measurement so that only the response from the protein-protein interactions are examined.

3.2. Fluorescence Measurements. The intensity of the emission from $10 \mu \mathrm{M}$ Thioflavin T with $0.5 \mathrm{mg} / \mathrm{mL} \alpha$-synuclein at $520 \mathrm{~nm}$ was recorded for 23 hours. The intensities recorded for the fluorescence measurements were scaled by the intensity from the blank wells in order to account for changes 


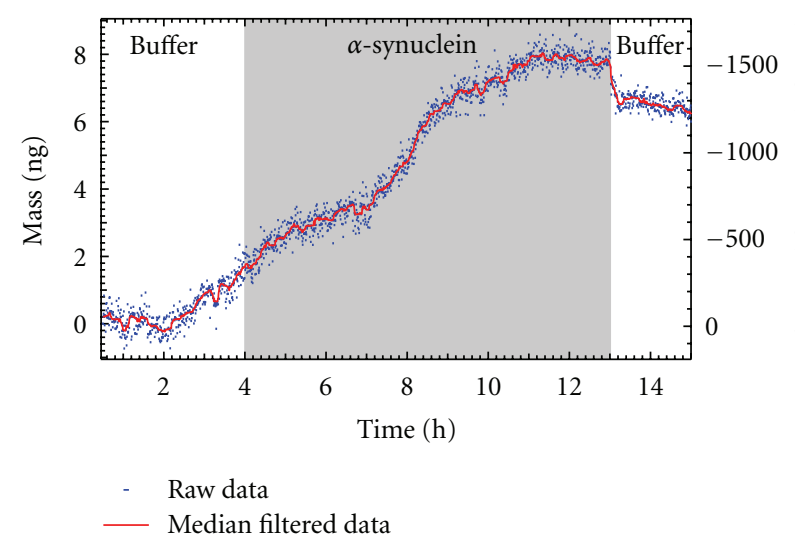

FIGURE 3: Graph of bound mass on the surface of the cantilever versus time. The frequency spectra recorded during the experiment were postprocessed using NOSEtools software to obtain the resulting plot of bound mass versus time. The scatter plot shows the raw data (with the reference cantilever subtracted), and the line shows the median box filter of the raw data (box size 23). The left axis shows the bound mass on the surface of the cantilever, and the right axis shows the corresponding differential frequency shift. The grey area indicates the period that $10 \mu \mathrm{g} / \mathrm{mL} \alpha$-synuclein in $20 \mathrm{mM}$ sodium phosphate buffer was flowing through the fluidic chamber at a rate of $3.3 \mu \mathrm{L} / \mathrm{min}$.

in the input power of the laser in the microplate reader. The intensity from the reference wells was then subtracted from the test wells to show the change in intensity due to the aggregation of the $\alpha$-synuclein. The experiment was carried out in duplicate, and the data from each time point was averaged (Figure 4). The error bars correspond to the result of the propagation of the standard error of the mean of the intensities through the analysis outlined above. After an initial lag phase of 7 hours, there is a steady increase of the average intensity recorded. This indicates that there is aggregation of the $\alpha$-synuclein during this time.

3.3. Discussion. These experiments show that it is possible to detect the aggregation of the protein $\alpha$-synuclein in a labelfree manner using functionalised microcantilevers operating in dynamic mode in a physiological liquid environment. The concentration of protein required to detect the aggregation using the label-free method is a factor 50 smaller than that used for the fluorescent method presented here. The total mass of protein required was also smaller despite the continuous flow method used for the cantilever measurements, with $50 \mu \mathrm{g}$ of protein being required per test well, while only $18 \mu \mathrm{g}$ of protein was passed through the cantilever fluidic chamber. In addition, no lag phase was observed during the cantilever measurements, whereas there was a seven hour lag phase observed in the fluorescence measurements.

The aggregation of the $\alpha$-synuclein on the surface of the cantilever was reproducible; however, the total mass of protein aggregated was heavily dependent on the conformation and density of the initial seeded monomers on the surface of the cantilever (data not shown).

It should be noted that approximately $6 \mathrm{ng}$ of the protein that was passed through the fluidic chamber was polymerised

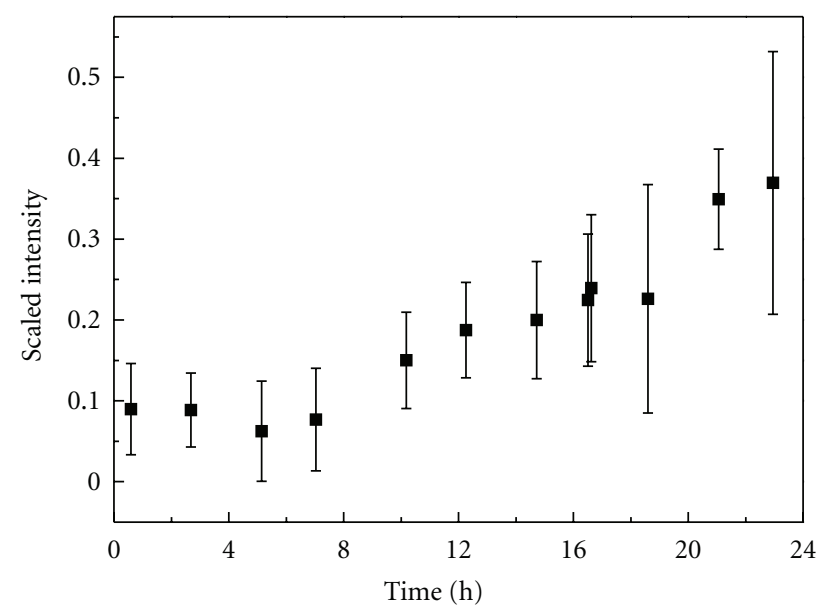

FIGURE 4: Scaled Intensity versus time for thioflavin $\mathrm{T}$ intensity measurements. The intensity of the emission from $10 \mu \mathrm{M}$ Thioflavin $\mathrm{T}$ with $0.5 \mathrm{mg} / \mathrm{mL} \alpha$-synuclein at $520 \mathrm{~nm}$ was recorded for 23 hours. The intensity was scaled by the blank measurement, and the Thioflavin $\mathrm{T}$ reference was subtracted from the test intensity measurement. The data shown is the average of the intensity from the two wells.

on the surface indicating that the continuous flow method is very wasteful. Employing a method where a smaller amount of $\alpha$-synuclein is used and the flow is stopped when the protein is in the fluidic chamber (which has a volume of $\sim 6 \mu \mathrm{L}$ ), a more efficient detection of the aggregation could be possible. However, if the aim is to determine the binding kinetics of the aggregation then such a stop flow situation could lead to incorrect conclusions as the rate that is obtained can heavily depend on the diffusion rate of the protein towards the surface of the cantilever within the fluidic chamber.

The sensitivity of a microcantilever for mass sensing allows detection of a very small mass of protein from the liquid flowed through the chamber (the current sensitivity of our device lies in the subnanogram regime in liquids). This can be advantageous when working with particularly expensive molecules or when the aim of the experiment is to detect molecules which are in very low concentrations in a natural, physiological environment.

The method and results presented here show a quantitative measurement of aggregation of the protein $\alpha$-synuclein on the surface of a microcantilever with an in situ reference in a physiological environment. This represents an improvement over other measurements of protein aggregation using microcantilevers reported in the literature [35]. As discussed in the Introduction, the static method is not suitable for determining the kinetics of the aggregation process. Further work will focus on determining the aggregation rates on the surface of the cantilever for a range of solution conditions and protein concentrations.

\section{Acknowledgements}

The authors would like to thank the School of Pharmacy and Pharmaceutical Sciences, Trinity College Dublin, for the use 
of the FLUOstar Optima microplate multidetection reader. This work was supported by Science Foundation Ireland under the CSET scheme SFI08/CE/I1432 and PI scheme SFI/09IN/1B2623.

\section{References}

[1] J. Parkinson, "An essay on the shaking palsy (reprinted)," The Journal of Neuropsychiatry and Clinical Neurosciences, vol. 14, no. 2, pp. 223-222, 2002.

[2] M. Goedert, " $\alpha$-synuclein and neurodegenerative diseases," Nature Reviews Neuroscience, vol. 2, no. 7, pp. 492-501, 2001.

[3] J. Lotharius and P. Brundin, "Pathogenesis of Parkinson's disease: dopamine, vesicles and $\alpha$-synuclein," Nature Reviews Neuroscience, vol. 3, no. 12, pp. 932-942, 2002.

[4] L. I. Golbe, G. Di Iorio, V. Bonavita, D. C. Miller, and R. C. Duvoisin, "A large kindred with autosomal dominant Parkinson's disease," Annals of Neurology, vol. 27, no. 3, pp. 276-282, 1990.

[5] R. Krüger, W. Kuhn, T. Müller et al., "Ala30Pro mutation in the gene encoding $\alpha$-synuclein in Parkinson's disease," Nature Genetics, vol. 18, no. 2, pp. 106-108, 1998.

[6] K. Wakabayashi, K. Tanji, F. Mori, and H. Takahashi, "The Lewy body in Parkinson's disease: molecules implicated in the formation and degradation of $\alpha$-synuclein aggregates," Neuropathology, vol. 27, no. 5, pp. 494-506, 2007.

[7] M. G. Spillantini, M. L. Schmidt, V. M. Y. Lee, J. Q. Trojanowski, R. Jakes, and M. Goedert, " $\alpha$-synuclein in Lewy bodies,” Nature, vol. 388, no. 6645, pp. 839-840, 1997.

[8] M. G. Spillantini, R. A. Crowther, R. Jakes, M. Hasegawa, and M. Goedert, " $\alpha$-synuclein in filamentous inclusions of Lewy bodies from Parkinson's disease and dementia with Lewy bodies," Proceedings of the National Academy of Sciences of the United States of America, vol. 95, no. 11, pp. 6469-6473, 1998.

[9] M. Baba, S. Nakajo, P. H. Tu et al., "Aggregation of $\alpha$-synuclein in Lewy bodies of sporadic Parkinson's disease and dementia with Lewy bodies," American Journal of Pathology, vol. 152, no. 4, pp. 879-884, 1998.

[10] R. A. Crowther, S. E. Daniel, and M. Goedert, "Characterisation of isolated $\alpha$-synuclein filaments from substantia nigra of Parkinson's disease brain," Neuroscience Letters, vol. 292, no. 2, pp. 128-130, 2000.

[11] P. H. Weinreb, W. Zhen, A. W. Poon, K. A. Conway, and P. T. Lansbury, "NACP, a protein implicated in Alzheimer's disease and learning, is natively unfolded," Biochemistry, vol. 35, no. 43, pp. 13709-13715, 1996.

[12] D. Eliezer, E. Kutluay, R. Bussell, and G. Browne, "Conformational properties of $\alpha$-synuclein in its free and lipid-associated states," Journal of Molecular Biology, vol. 307, no. 4, pp. 10611073, 2001.

[13] E. Masliah, E. Rockenstein, I. Veinbergs et al., "Dopaminergic loss and inclusion body formation in $\alpha$-synuclein mice: implications for neurodegenerative disorders," Science, vol. 287, no. 5456, pp. 1265-1269, 2000.

[14] E. Maries, B. Dass, T. J. Collier, J. H. Kordower, and K. Steece-Collier, “The role of $\alpha$-synuclein in Parkinson's disease: insights from animal models," Nature Reviews Neuroscience, vol. 4, no. 9, pp. 727-738, 2003.

[15] M. B. Feany and W. W. Bender, "A Drosophila model of Parkinson's disease,” Nature, vol. 404, no. 6776, pp. 394-398, 2000.

[16] W. Hoyer, T. Antony, D. Cherny, G. Heim, T. M. Jovin, and V. Subramaniam, "Dependence of $\alpha$-synuclein aggregate morphology on solution conditions," Journal of Molecular Biology, vol. 322, no. 2, pp. 383-393, 2002.

[17] H. Naiki, K. Higuchi, M. Hosokawa, and T. Takeda, "Fluorometric determination of amyloid fibrils in vitro using the fluorescent dye, thioflavine T," Analytical Biochemistry, vol. 177, no. 2, pp. 244-249, 1989.

[18] H. LeVine, "Quantification of $\beta$-sheet amyloid fibril structures with thioflavin T," Methods in Enzymology, vol. 309, pp. 274284, 1999.

[19] R. Demaimay, J. Harper, H. Gordon, D. Weaver, B. Chesebro, and B. Caughey, "Structural aspects of congo red as an inhibitor of protease-resistant prion protein formation," Journal of Neurochemistry, vol. 71, no. 6, pp. 2534-2541, 1998.

[20] M. K. Ghatkesar, T. Braun, V. Barwich et al., "Resonating modes of vibrating microcantilevers in liquid," Applied Physics Letters, vol. 92, no. 4, Article ID 043106, 2008.

[21] R. McKendry, J. Zhang, Y. Arntz et al., "Multiple labelfree biodetection and quantitative DNA-binding assays on a nanomechanical cantilever array," Proceedings of the National Academy of Sciences of the United States of America, vol. 99, no. 15, pp. 9783-9788, 2002.

[22] F. Huber, M. Hegner, C. Gerber, H. J. Güntherodt, and H. P. Lang, "Label free analysis of transcription factors using microcantilever arrays," Biosensors and Bioelectronics, vol. 21, no. 8, pp. 1599-1605, 2006.

[23] L. M. Lechuga, J. Tamayo, M. Álvarez et al., "A highly sensitive microsystem based on nanomechanical biosensors for genomics applications," Sensors and Actuators B, vol. 118, no. 1-2, pp. 2-10, 2006.

[24] J. Mertens, C. Rogero, M. Calleja et al., "Label-free detection of DNA hybridization based on hydration-induced tension in nucleic acid films," Nature Nanotechnology, vol. 3, no. 5, pp. 301-307, 2008.

[25] D. Ramos, M. Arroyo-Hernández, E. Gil-Santos et al., "Arrays of dual nanomechanical resonators for selective biological detection," Analytical Chemistry, vol. 81, no. 6, pp. 2274-2279, 2009.

[26] B. Ilic, Y. Yang, and H. G. Craighead, "Virus detection using nanoelectromechanical devices," Applied Physics Letters, vol. 85, no. 13, pp. 2604-2606, 2004.

[27] N. Nugaeva, K. Y. Gfeller, N. Backmann, H. P. Lang, M. Düggelin, and M. Hegner, "Micromechanical cantilever array sensors for selective fungal immobilization and fast growth detection," Biosensors and Bioelectronics, vol. 21, no. 6, pp. 849-856, 2005.

[28] K. Y. Gfeller, N. Nugaeva, and M. Hegner, "Rapid biosensor for detection of antibiotic-selective growth of Escherichia coli," Applied and Environmental Microbiology, vol. 71, no. 5, pp. 2626-2631, 2005.

[29] K. Y. Gfeller, N. Nugaeva, and M. Hegner, "Micromechanical oscillators as rapid biosensor for the detection of active growth of Escherichia coli," Biosensors and Bioelectronics, vol. 21, no. 3, pp. 528-533, 2005.

[30] D. Ramos, J. Tamayo, J. Mertens, M. Calleja, L. G. Villanueva, and A. Zaballos, "Detection of bacteria based on the thermomechanical noise of a nanomechanical resonator: origin of the response and detection limits," Nanotechnology, vol. 19, no. 3, Article ID 035503, 2008.

[31] P. S. Waggoner, M. Varshney, and H. G. Craighead, "Detection of prostate specific antigen with nanomechanical resonators," Lab on a Chip, vol. 9, no. 21, pp. 3095-3099, 2009.

[32] N. Backmann, C. Zahnd, F. Huber et al., "A label-free immunosensor array using single-chain antibody fragments," 
Proceedings of the National Academy of Sciences of the United States of America, vol. 102, no. 41, pp. 14587-14592, 2005.

[33] T. Braun, M. K. Ghatkesar, N. Backmann et al., "Quantitative time-resolved measurement of membrane protein-ligand interactions using microcantilever array sensors," Nature Nanotechnology, vol. 4, no. 3, pp. 179-185, 2009.

[34] T. Braun, N. Backmann, M. Vögtli et al., "Conformational change of bacteriorhodopsin quantitatively monitored by microcantilever sensors," Biophysical Journal, vol. 90, no. 8, pp. 2970-2977, 2006.

[35] T. P. J. Knowles, W. Shu, F. Huber et al., "Label-free detection of amyloid growth with microcantilever sensors," Nanotechnology, vol. 19, no. 38, Article ID 384007, 2008.

[36] F. J. Elmer and M. Dreier, "Eigenfrequencies of a rectangular atomic force microscope cantilever in a medium," Journal of Applied Physics, vol. 81, no. 12, pp. 7709-7714, 1997.

[37] J. E. Sader, "Frequency response of cantilever beams immersed in viscous fluids with applications to the atomic force microscope," Journal of Applied Physics, vol. 84, no. 1, pp. 6476, 1998.

[38] T. Braun, V. Barwich, M. K. Ghatkesar et al., "Micromechanical mass sensors for biomolecular detection in a physiological environment," Physical Review E, vol. 72, no. 3, Article ID 031907, 9 pages, 2005.

[39] C. A. Van Eysden and J. E. Sader, "Resonant frequencies of a rectangular cantilever beam immersed in a fluid," Journal of Applied Physics, vol. 100, no. 11, Article ID 114916, 2006.

[40] C. A. Van Eysden and J. E. Sader, "Small amplitude oscillations of a flexible thin blade in a viscous fluid: exact analytical solution," Physics of Fluids, vol. 18, no. 12, Article ID 123102, 2006.

[41] C. A. Van Eysden and J. E. Sader, "Frequency response of cantilever beams immersed in viscous fluids with applications to the atomic force microscope: arbitrary mode order," Journal of Applied Physics, vol. 101, no. 4, Article ID 044908, 2007.

[42] C. A. Van Eysden and J. E. Sader, "Frequency response of cantilever beams immersed in compressible fluids with applications to the atomic force microscope," Journal of Applied Physics, vol. 106, no. 9, Article ID 094904, 2009.

[43] C. A. Van Eysden and J. E. Sader, "Compressible viscous flows generated by oscillating flexible cylinders," Physics of Fluids, vol. 21, no. 1, Article ID 013104, 2009.

[44] M. K. Ghatkesar, E. Rakhmatullina, H. P. Lang, C. Gerber, M. Hegner, and T. Braun, "Multi-parameter microcantilever sensor for comprehensive characterization of Newtonian fluids," Sensors and Actuators B, vol. 135, no. 1, pp. 133-138, 2008.

[45] S. Kim and K. D. Kihm, "Experimental verification of the temperature effects on Sader's model for multilayered cantilevers immersed in an aqueous medium," Applied Physics Letters, vol. 89, no. 6, Article ID 061918, 2006.

[46] L. Nicu, M. Guirardel, F. Chambosse et al., "Resonating piezoelectric membranes for microelectromechanically based bioassay: detection of streptavidin-gold nanoparticles interaction with biotinylated DNA," Sensors and Actuators B, vol. 110, no. 1, pp. 125-136, 2005.

[47] M. K. Ghatkesar, V. Barwich, T. Braun et al., "Higher modes of vibration increase mass sensitivity in nanomechanical microcantilevers," Nanotechnology, vol. 18, no. 44, Article ID 445502, 2007.

[48] A. Bietsch, J. Zhang, M. Hegner, H. P. Lang, and C. Gerber, "Rapid functionalization of cantilever array sensors by inkjet printing," Nanotechnology, vol. 15, no. 8, pp. 873-880, 2004.
[49] P. Wagner, M. Hegner, P. Kernen, F. Zaugg, and G. Semenza, "Covalent immobilization of native biomolecules onto $\mathrm{Au}(111)$ via N-hydroxysuccinimide ester functionalized selfassembled monolayers for scanning probe microscopy," Biophysical Journal, vol. 70, no. 5, pp. 2052-2066, 1996.

[50] T. Braun, M. K. Ghatkesar, V. Barwich et al., "Digital processing of multi-mode nano-mechanical cantilever data," Journal of Physics, vol. 61, no. 1, pp. 341-345, 2007.

[51] T. Braun, NOSEtools Software Homepage, http://web.me.com/brunobraun/NOSEtools/Home.html.

[52] T. Braun, F. Huber, M. K. Ghatkesar et al., "Processing of kinetic microarray signals," Sensors and Actuators B, vol. 128, no. 1, pp. 75-82, 2007. 

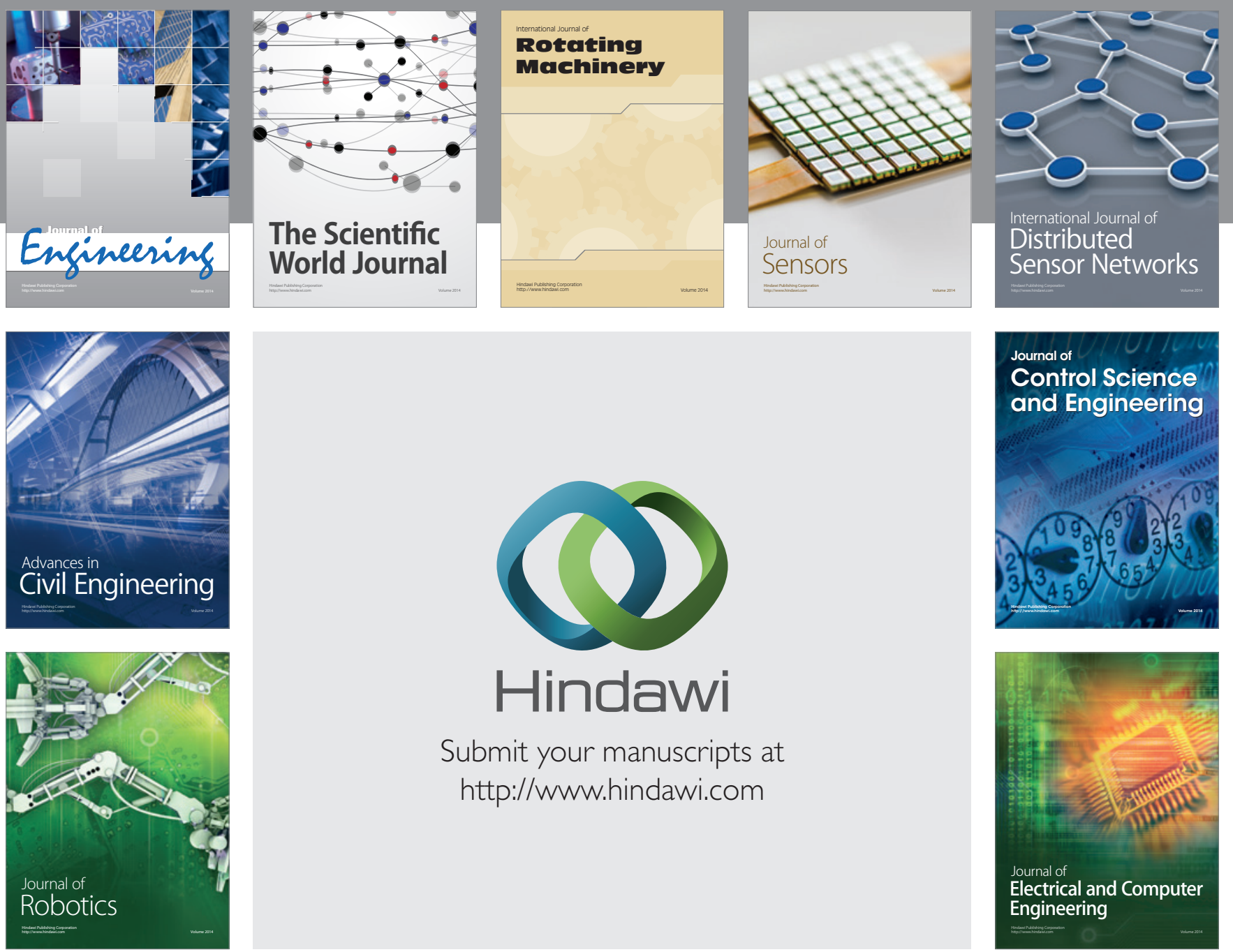

Submit your manuscripts at

http://www.hindawi.com
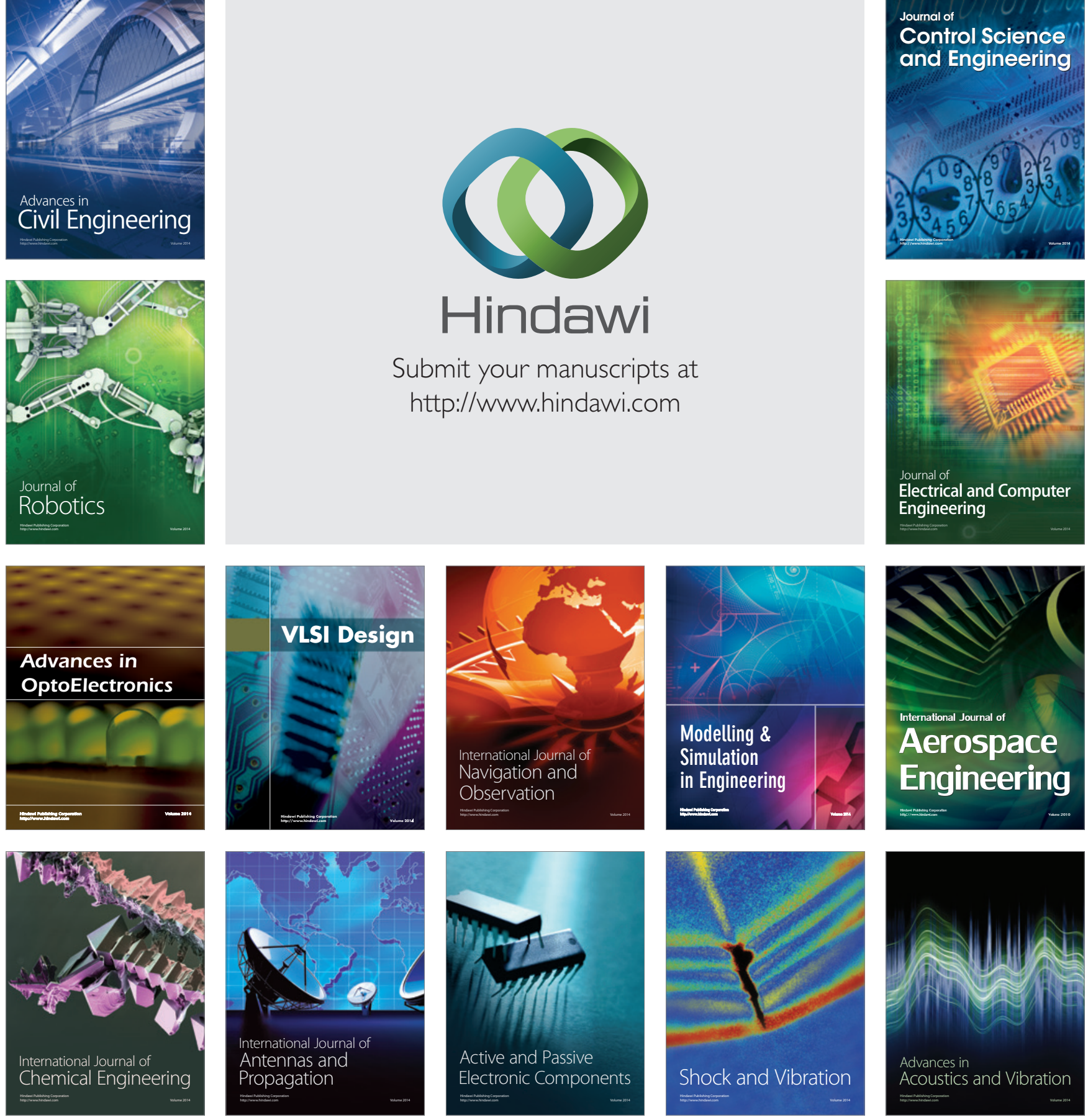